\title{
Affection not affliction: The role of emotions in information systems and organizational change
}

\author{
Kathy McGrath \\ School of Information Systems, Computing and Mathematics, \\ Brunel University, Uxbridge, Middlesex, UK
}

Tel: +44 (0) 1895266047

Fax: +44 (0) 1895251686

E-mail: Kathy.McGrath@brunel.ac.uk

\begin{abstract}
Most IS research in both the technical/rational and socio-technical traditions ignores or marginalizes the emotionally charged behaviours through which individuals engage in, and cope with the consequences of, IS practice and associated organizational change. Even within the small body of work that engages with emotions through particular conceptual efforts, affections are often conceived as a phenomenon to be eradicated - an affliction requiring a cure. In this paper, I argue that emotions are always implicated in our lived experiences, crucially influencing how we come to our beliefs about what is good or bad, right or wrong. I draw from the theoretical work of Michel Foucault to argue for elaborating current notions of IS innovation as a moral and political struggle in which individuals' beliefs and feelings are constantly tested. Finally, I demonstrate these ideas by reference to a case study that had considerable emotional impact, and highlight the implications for future work.
\end{abstract}

Keywords: affection, emotionality, ethical behaviour, information systems, moral conduct, organizational change. 


\section{INTRODUCTION}

One of the most striking features of twentieth-century research on work in organizations and its associated technologies is the rise to dominance of a rationalized model of human behaviour. People are seen as instrumental actors, obeying particular logics designed to promote organizational effectiveness and profit maximization, supported by robust and reliable technical artefacts. In the early part of the century, these artefacts were evident as power-driven machines in factories, which by then had become an integral part of the production process; now they are more prevalent as information and communication technologies (ICTs) - in effect, the sine qua non of modern business enterprises.

Yet, even while research has focused on changes in the nature of work and the technologies developed and deployed for its accomplishment, it has done little to advance our understanding of the emotions involved in work situations beyond Weber's notion of the dehumanized bureaucrat. 'Sine ira et studio, without hatred or passion, and hence without affection or enthusiasm' (Weber 1978, p.225 cited in Albrow 1997, p.93) now seems to describe a wide variety of calculative agents pursuing the reified goal of organizational effectiveness.

One might conclude that recent moves within some disciplines - such as sociology and organization studies - to give attention to emotions (Albrow 1997; Fineman 1993; 2000a; Hochschild 1979; 1983) are an effort to give voice to a phenomenon that has been unacknowledged in writing up to this point. As Albrow (1997) convincingly argues, this would be a narrow reading of history. Rather, such work may be seen as an attempt to recover knowledge, to redress 'a twentieth-century aberration, indeed an expression of its rationalism, but at odds with earlier understanding of organization' ( $p$. 94). In effect, ideas about scientific management (Taylor 1911) and bureaucratic forms of organizing (Weber 1947) have been harnessed to provide a passionless paradigm for organizational analysis within the rationalization project of modernity. Eighteenth and nineteenth century writers' concerns ${ }^{1}$ with how organized cooperation among individuals - for work, charitable, religious and other purposes - generated strong and productive passions as well as bitter resentments have been progressively eliminated or mentioned only to show how to bring such powerful emotions under control.

Albrow's concerns about the way that organizational analysis, and much of sociological analysis, have developed seem even more applicable to the field of information systems (IS). With its early roots in a sub-field of computer science, and strongly influenced by concepts from a 'hard' version of general systems theory (von Bertalanffy 1968) deriving from mathematics and engineering, the objects of study were not only passionless but also inanimate. Although socio-technical systems theory (Trist et al. 1963) brought human, as well as technical and environmental, issues under consideration, effort was then directed towards achieving consensus among often conflicting concerns, subsuming emotional aspects of human behaviour within the rationalized goal of improving organizational performance.

With the rise of the business schools, information systems was incorporated as a major component of most business studies and business administration courses, and IS research became closely aligned with management studies and influenced specifically by concepts from organization theory and economics. In this way, the rationalism of

\footnotetext{
${ }^{1}$ One of the most well known examples - in European social history at least - is Marx and Engels's (1977[1888]) Communist Party Manifesto, exhorting: 'The proletarians have nothing to lose but their chains. They have a world to win. Working men of all countries, unite!' (p.74).
} 
organizational analysis came to bear upon IS research (Avgerou 2000). Moreover, influenced by ideas from industrial and transaction economics (Williamson 1975; 1981; 1985), IS research began to focus on how calculative agents could manipulate industry structure using ICTs and maximize individual and organizational utility to enhance competitiveness.

In this context, a range of models and methodologies was developed for systems development and IS planning (DeMarco 1979; Porter and Millar 1985; Yourdon 1989), reflecting the mix of concerns that had preoccupied the field up to that point: the construction of reliable ICT artefacts, administrative control and economic gain.

As the IS field matured, some plurality of themes and theoretical perspectives started to emerge. It was recognised that human behaviour does not always comply with the technical/rational models highlighted above (Franz and Robey 1984; Markus 1983; Markus and Bjørn-Andersen 1987). Such behaviours were identified as informal or political, as problematic attitudes involving some conflict. However, little reference was made to the emotions involved, which in general were not seen as substantive enough in their own right to warrant analytical attention. Rather, rationally minded professionals were advised to adjust their strategies to take account of the disruptive behaviours.

Since the late 1980s a stream of work has been developed that makes a substantial break with the technical/rational tradition of the IS field. These non-instrumental analyses are informed by a range of contemporary social theories and debates from across the social sciences - sometimes referred to as the new socio-technical theory (Avgerou 2002). They point out that technical/rational models misrepresent the real processes of deploying and using ICT artefacts and making associated changes to organizational structures and practices - referred to in this paper with the term IS innovation. They juxtapose other types of behaviour - spontaneous action, tacit knowledge, political action - not as problematic attitudes that subvert the technically reasoned professional activities, but as constructive behaviour observed in cases of successful innovation (Ciborra and Associates 2000; Knights et al. 1997; Suchman 1987). More generally, they contribute to a body of IS knowledge that has come to address ICTs and organizations in terms of individual actors' behaviour embedded in social context, that is, human interactions supported or inhibited by institutionalized modes of practice (Orlikowski 2000; Walsham 1993).

Nevertheless, most of these studies focus on cognitive aspects of human action and intentional behaviour, even though this behaviour is seen not to be limited to technical reasoning but to involve political alignments and improvisational elements. As in previous streams of work, the emotional dimensions of human existence are at most marginally acknowledged. Thus, by narrowing human agency to its cognitive dimensions, most IS studies retain an impoverished conception of the relationship of IS innovation to the human condition, unable to consider the totality of human capacities that are either positively or negatively engaged with innovation processes.

In short, the prominent core of rationalized professional and academic knowledge within the IS field has frequently been shown as inadequate to cope with the complexity of particular IS projects (Avgerou 2002; Ciborra 2002; Walsham 2001). Yet even among researchers who have adopted a more context-specific view of IS innovation, few have considered directly issues involving emotionality. However, part of the social, political and cultural context that these authors would highlight is the emotional medium in which action takes place. An understanding of how emotions come to bear on particular instances of IS innovation can assist the development of a contextualized professional practice and aid the transfer of knowledge from one domain to another, such as from private to public sector or industrialized to developing countries. 
The remainder of this paper is organized as follows. In section 2, I examine some recent efforts to raise awareness of the role of emotions in relation to ICTs and/or work in organizations. Then, drawing from Foucault's notion of the ethical subject, I outline some conceptual premises for addressing emotions as a constituent aspect of human conduct, deeply implicated in how we come to our beliefs about what is good or bad, right or wrong. In section 3 , I describe the conduct of this study and the research setting in which I carried it out, highlighting how my theoretical perspective shifted as I began to acknowledge the key role of emotions in this case. In the analysis, I examine the conflicting notions of ethical behaviour at work in the case, focusing on the emotions associated with a patient care role and how they were disrupted by a modernization initiative involving the use of ICTs. Then I discuss how the emotions involved reveal the marginalization of substantive moral concerns that only later were acknowledged by policy makers. Finally, in the conclusions, I summarize how a Foucauldian perspective on moral conduct alters technical/rational assumptions about the purposes an IS innovation serves and the strategies and tactics deployed to accomplish them.

\section{PERSPECTIVES ON EMOTIONS}

Within IS and related fields concerned with the study of work in organizations and its associated technologies, organizational rationalism - and hence how best to deploy an organization's resources to compete effectively in a market economy - has become the dominant research theme (Albrow 1997; Avgerou 2000). Nevertheless, this dominance is being challenged by alternative research agendas, which engage in noninstrumental analyses of the emotional domain of human behaviour. This section gives a flavour only of the growing interest in emotions research relating to ICTs and work in organizations, so as to position the contribution of this paper.

Emanating from the sociology of organization, Hochschild's studies of emotional labour (Hochschild 1979; 1983) have highlighted the psychological damage that can result from efforts to make front line staff conform to managerially prescribed rules of emotional expression towards customers. Seminal for streams of research in organization and management studies, her work perhaps inevitably inspired the pursuit of emotion engineering (engendering the 'right' way to feel) as well as interest in the nature - rather than the management - of emotions in organizations (Meyerson 2000). Several contributors to Fineman's edited volumes (Fineman 1993; 2000a) also engage with emotion in organizations in the non-managerialist way intended in this paper. Moreover, some research on workplace emotion has considered information technology as one of several material objects that mediate our work lives and can be invested with emotional qualities (Gagliardi 1999; Strati 1999). In general, though, organization and management studies have tended not to use an emotional lens to focus on ICTs.

Elsewhere, sociologists have explored the emotions relating to the deployment and use of IT in society (Alexander et al. 1992; Brosnan 1998). Moreover, Zuboff's (1988) much referenced work deals as much with actors' feelings as they confront the new technology innovations as it does with their perceptions and behaviours, even though it is less frequently cited in the former regard. Researchers of human-computer interaction, often drawing upon reference theories from psychology, have become increasingly interested in exploring the affective aspects of computing (Picard 1997). Yet, there is still little evidence of researchers of IS innovation giving much analytical attention to the affective domain relative to other concerns, as discussed next. 


\subsection{The theme of emotions in the IS innovation literature}

The IS innovation literature reveals three main attitudes to the emotional domain in which IS practice and associated organizational change initiatives unfold. The dominant position is to say nothing of emotions, suggesting that IS research and professional practice are purely rational processes, devoid of affections. This position is prevalent in much of the literature that deals with techniques and frameworks for systems development, strategic planning, project management and outsourcing.

Another prevalent attitude is to mention emotions 'en passant', acknowledging that affections are involved in the IS innovation process but engaging in no (substantive) effort to give them analytical attention. Much research on conflict in organizations, resistance to change and technology acceptance adopts this position. Research attention is focused on actors' cognitive responses to ICTs (for example, Orlikowski 2000), with the result that their emotions seem non-substantive - descriptors of the context, subsumed in some more important concern, but not legitimate in their own right. In such research, the nature of emotions remains unexplored and hence the role they play in IS innovation continues to be unclear.

The attitude adopted in this paper is to engage with emotions through a specific conceptual effort. Studies of this type vary in the significance and the role they attribute to emotions. For example, in Trauth and Jessup's (2000) study of a group support system for anonymous electronic brainstorming and voting, examining the affective responses of participants was one aspect of the researchers' agenda. Their analysis also addressed cognitive and behavioural responses, and compared insights derived from contrasting methodological approaches to the study. They concluded that richer insights on the case were obtained when participants' affections were taken into account.

Wastell has written several papers where the actors' emotions are the core theme. He addresses the social defences that individuals and organizations adopt to a range of emotions, generally anxiety-related (Wastell 1996; 1999; 2003). His work shows how established discourses and knowledge can be used as such defences during IS innovation, blocking genuine engagement with the tasks at hand and ultimately subverting related organizational change. Consistent with a psychoanalytic perspective, he sees anxiety and the behaviour it induces as dysfunctional or irrational, and seeks to break down the defensive processes, as in the clinical application of such research.

Giddens argues that anxiety is existential in his writings on modernity and its consequences (Giddens 1990; 1991). Typically, such anxiety floats freely, largely untroublesome to individuals owing to their frameworks of ontological security - that is, the routines of their everyday practice. However, if they are unable to, or prevented from, carrying out these routines - say, by an IS innovation - their anxiety can intensify to fear, which may become fixed on the object or situation perceived as threatening.

Barrett and Walsham (1999) use the concept of existential anxiety to examine a crisis of identity among brokers and underwriters when a new information system was introduced in the London Insurance Market. Anxiety heightened because the new system did away with emotional cues previously relied upon to assess risk in face to face situations - in effect, the introduction of ICTs disturbed individuals' frameworks of ontological security. In that paper, the emotional lens is one part of a conceptual scheme developed by the authors for examining the link between ICTs and work transformation.

More broadly, Ciborra (2002) draws from Heidegger to argue that we always act within an emotional medium. We have a fundamental attunement with a situation - a 
way of encountering the world - through a mood ${ }^{2}$; and even though moods can change, we are never without one (p.161). In this view, purely rational action is not possible. Moreover some moods are intense, such as panic and profound boredom (when we are empty, and want nothing from a particular situation); in this form of attunement alternative courses of action are closed off, and any type of effective action becomes problematic. Conversely, when moods are not intense we engage in everyday practices, in an effort to drive a mood away (ibid.), as when we enact the established routines in our framework of ontological security (Giddens 1991) to cope with anxiety.

In this paper, I argue that emotions colour every encounter we have with the world. Thus, in my effort to understand how IS innovation unfolds in organizations, I find a need to try to make sense of actors' feelings and affections - not in a managerialist inspired attempt to control them, but to understand their nature and the role they play in the innovation process. Narrowing our focus on IS innovation to the cognitive domain risks developing advice and practice that may be not just limited but even blatantly inappropriate. Rather, in an effort to take account of the range of human experiences that can be brought to bear on such situations, I elaborate a Foucauldian perspective on emotions as the conceptual scheme that informs this research.

\subsection{A Foucauldian perspective on emotions}

Michel Foucault is best known for his work on the relationship between power and knowledge. That work has been used by several researchers to explore the relationship in its cognitive dimensions (for example, Bloomfield et al. 1997; Knights and Murray 1994). Nevertheless, one can hardly read his descriptions of the execution of Damiens (Foucault 1977), or the practices in Charcot's clinic (Foucault 1978), without wanting to ask about the emotions of the subjects and spectators at these events, and how their feelings influenced the way that criminality and sexuality came to be dealt with in later years. So, although Foucault left it until late in his life to comment on how individuals engage with the affective domains of their lives, his earlier descriptions of madness, illness and criminality, and how societies came to deal with them, are so poignant that one senses this concern throughout his work.

In the last two volumes of The History of Sexuality (Foucault 1985; 1986), he made this concern explicit. Furthermore, he developed his views on specific emotional aspects of human conduct in relation to his position on knowledge and reason, and how the power relations operating in a particular social context sustain or change them.

\subsubsection{On emotionality and its relationship with rationality}

In Foucault's perspective, an individual's rational and emotional conduct is formed within a society's systems of power, knowledge and morality. His studies of specific areas of social practice (Foucault 1971; 1973; 1977; 1978; 1985; 1986) reveal a plurality of rational actions and emotionally charged behaviours relating to insanity, illness, criminality and sexuality. These works do not uncover universal truths about human nature or society; rather, they reveal knowledge that came to be believed as true and humans striving for moral conduct under dynamics of power in particular historical conditions.

Foucault linked knowledge and power through discourse, showing that the discursive practices of a particular society, and hence its beliefs about appropriate behaviour, are linked with institutions, economic requirements and political issues and

\footnotetext{
${ }^{2}$ Writers suggest that affective phenomena include emotions, moods, and dispositions (Oatley and Jenkins 1996). While some authors define these phenomena in terms of their duration or stability, intensity, and target, others are less prescriptive.
} 
enmeshed in the power dynamics of multiple actors. He used the term 'regime of truth' to convey this notion of a socially constructed, power constituted legitimation of the knowledge that supports a society's institutions (Foucault 1980). Within a regime of truth power relations are unequal among individuals, but not essentially repressive: they may involve the deployment of physical force, but in modern Western societies the more common form is the use of disciplinary techniques by institutions such as education and state administration. Hence power mechanisms may be seen as resulting in useful order and compliance with common patterns of socially acceptable behaviour; however, they may also be resisted. These instances are supported by 'subjugated knowledges' - that is, ways of arguing and acting that have been disqualified as naïve or inadequate in the dynamics of forming the regime of truth.

Following on from this position, Foucault addressed the specific question of how people came to accept particular practices - what role individuals themselves played in shaping their lives in their societies. Thus, he broadened the power/knowledge perspective by shifting attention to ethical behaviour, specifically to sexual ethics - a highly emotional domain of human conduct. He argued that such behaviour involves an effort of self-discipline, pragmatically constructed according to how individuals problematize who and what they are in their present situation. In effect, ethical behaviour is not just a matter of what beliefs a particular society holds about appropriate conduct, it is also a matter of how individuals choose to participate as moral agents how they constitute themselves as subjects of specific beliefs about what is right and wrong. Such self-disciplining is inevitably influenced by each individual's capacity to act within the power dynamics of their particular social circumstances.

In Foucault's view, moral conduct is socially constructed and power constituted, but not determined in a purely cognitive process. In the societies he studied - classical Greek, Hellenistic, and Roman - sexual ethics is seen as an exercise of freedom by subjects concerned with a general problematization of getting their lives right, which involves aesthetic values and feelings about the quality of the relationships they have with themselves and others. Thus, in Foucault's notion of ethics, beliefs and feelings are intertwined in a self-disciplinary regime such that rationality and emotionality constitute each other. Moreover, his ideas on moral conduct were not limited to the sexual ethics of past civilizations. Reflecting on his work in progress shortly before his death, he argued: 'you can say, in general, that in our society the main field of morality, the part of ourselves which is most relevant for morality, is our feelings' (Foucault 1984, p.352).

\subsubsection{Addressing emotions in human behaviour}

Foucault's work on the subject and affections, and hence on ideas of personal and voluntary rules of conduct that are morally laden, opens a route for understanding emotions in human behaviour. The analytical direction for this understanding is provided by his notion of the ethical subject ${ }^{3}-$ the individual engaged in self-discipline, in which one strives for a better life through a process of reflexive engagement and action (Foucault 1985; 1986). This effort involves adopting various self-practices to

\footnotetext{
${ }^{3}$ Foucault's notion of ethics is radically opposed to the Kantian view of an individual, autonomous agent who makes decisions and moral judgements on the basis of rational considerations (Huijer 1999). The Kantian view has been particularly popular in research on business ethics and, to a lesser extent, within the field of computer ethics (Bell and Adam 2004). In Foucault's work, however, the individual as someone who acts in line with moral codes determined a priori is replaced by a view of human agents as subjects enmeshed in a network of moral relationships where ethical behaviour is situated. In this view, Foucault has much in common with the Heideggerean notion of 'situated', which refers not just to the emerging circumstances of the surrounding world, but also to the inner situation (the affectedness) of the actor (Ciborra 2006).
} 
achieve the desired transformation of one's existence. These 'techniques of the self' have four interrelated aspects: a) problematization; b) mode of subjection; c) working on oneself; and d) a focus on transforming one's life into a work of art.

Problematization deals with the question of which part of one's life requires ethical care. Although attention may be directed towards a desire or an act, Foucault (1984) emphasizes that, in modern society, notions of moral conduct generally reside in our feelings about the quality of our relationships with others. Therefore, our emotions are key to telling us whether we are taking 'good' care of those to whom we accept a moral responsibility in life. The 'mode of subjection' is concerned with how individuals come to recognize their moral responsibilities. Such ways include belonging to a particular group, seeing the responsibilities as quasi-juridical, or having a perception of self that requires such acceptance. 'Working on oneself' refers to the critical and active attitude to transform oneself through the use of self-practices, which may include moderating one's behaviours, renouncing certain acts, or continually monitoring and questioning how one behaves and why. Finally, the 'focus on transforming one's life into a work of art' addresses the direction, or mode of being, to which individuals aspire when they behave in an ethical way - their ultimate goal, personally defined.

Summarizing Foucault's ideas, how people act stems from the beliefs on right or wrong sustained by their social context, but they participate in shaping their lives in their societies according to how they make themselves the subject of their actions. Emotions are strongly implicated in this process of how individuals care for their lives. Their self-disciplinary efforts are aesthetically oriented towards desired goals, personally defined, in which their affections are not problematic to them. In short, individuals are reflective actors whose beliefs and feelings are constantly tested in the domain of their professional and personal lives. They experience moral challenges which trigger specific tactics that are emotionally charged, expressing not only how they judge the value of prevailing discourses in their society but also how they assess the capacity to act afforded to them by their particular social circumstances.

In this paper, I demonstrate these ideas by reference to the case introduced in the next section. That episode was part of a larger research study that addressed the question: How does IS innovation unfold when cultural change of an organisation is attempted, that is, when an effort is made to disrupt the constituting discourses for a community so that the basis of truth is altered? The specific aspect of interest reported here is the nature and role of emotions in the unfolding of the innovation processes.

\section{RESEARCH CONDUCT AND SETTING}

\subsection{Conceptual approach}

This research was conducted with the London Ambulance Service (LAS) eight years after the disastrous collapse of the LASCAD (London Ambulance Service Computer Aided Dispatch) system in 1992 (Beynon-Davies 1995; Page et al. 1993). That episode is an important part of the LAS's history, and therefore I enquired about it as a crucial piece of the context for the more recent IS projects on which my research was focusing.

The study of which the LASCAD episode is a part constructed a historical narrative covering 20 years of IS innovation at the LAS. That study adopted a contextualist approach (Pettigrew 1990) to studying the IS-related organizational change associated with modernization of the British National Health Service (NHS) since the early 1980s. Central to the approach was the aim to develop a rich understanding of the history and 
culture of the organization, as the basis for an examination of key issues within a critical epistemology (Alvesson and Deetz 2000).

The research was informed from an early stage by Foucault's theory of power/knowledge (Foucault 1977; 1978; 1980). These concepts readily captured the power dynamics among individual health service organizations and British government policy, institutions and funding mechanisms. Moreover, the concept of 'regimes of truth' conveyed not only the sense of the modernization initiatives ongoing in the NHS for over two decades, but also the notion of the existing health service culture. In this way Foucault's theory of power/knowledge may be seen as providing sensitizing concepts to the research, which were further refined as the empirical work progressed (Lee and Baskerville 2003; Walsham 1995).

The major refinement occurred when I was prompted to give analytical attention to the emotional domain of human conduct. I had not approached this organisation sensitized in any way by theoretical concepts of emotion. Yet during interviews with, and observations of, LAS staff I had witnessed their emotions and discussed their feelings with them. Many study participants provided me with their accounts of the 1992 episode, which they recalled as an intense emotional experience, the memory of which had stayed with them during the 8 years that had elapsed between when the episode occurred and when I first met them. Moreover, it was clear that despite a number of more successful implementations since then, IS innovation in the organization continued to be a highly charged emotional experience. At this time, I began to develop a thesis that individuals' lived experiences of $1992 \mathrm{had}$ been traumatic, and that their emotion had endured in some form and intensified when they approached future IS implementations, specifically those efforts I was observing during this study. In an organization where the average length of service in 2001 was 9 years, the number of staff with experience of both episodes was significant.

Nevertheless, it was by no means obvious how to theorize the emotion I found, not least because I continued to believe that my original theoretical argument, based on a cognitive understanding of Foucault's theory of power/knowledge, was relevant to the case in a wider sense. I looked for other concepts to express my findings. Ideas from the literature on emotions provided further insights, but then my argument became fragmented, in effect drawing from two distinct literatures with disparate concerns.

The initiative to persist with a Foucauldian perspective came from Fineman's introduction (2000b) to his second edition of Emotion in Organizations - expressing the view that Foucault's ideas have yet to be exploited for emotionality. The last two volumes of The History of Sexuality (Foucault 1985; 1986) - two examples among Foucault's work that are comparatively overlooked in the literature - provided the link for making the relationship among knowledge, power and human conduct (both rational and emotional). Thus, I established a continuity between two notions derived from diverse literatures: first, that IS innovation is always enmeshed in the dynamics of knowledge and power, and second, that we always act under the influence of emotions, even though we may be only dimly aware of them. While these ideas had initially led me to the view that our ways of arguing and acting are not purely cognitive, it was through Foucault's work on ethical conduct that I came to see IS innovation as a moral and political struggle in which individuals' beliefs and feelings are constantly tested.

\subsection{Research setting}

The LASCAD case has been one of the most high-profile IS failures in the UK public sector (Beynon-Davies 1995; Silva and Backhouse 1997; Wastell and Newman 1996). In a broad sense it must be seen in light of the British government's policy to 
modernize the National Health Service (NHS). This process has been ongoing for more than two decades and has been pursued by Conservative and Labour governments, albeit with different emphases on the meaning of modernization. Overall, the principle that the NHS should be open to all and free at the point of access is a continuing theme ${ }^{4}$. Furthermore, ministers repeatedly articulate joint needs to change the culture of the health service and mobilize the potential of information technology. Yet, different governments have had their own policy agendas for the transformation of a centralized, publicly funded body into a model of modern health care provision.

In the early 1990s, two key reports summarized the then Conservative government's agenda. The Griffiths report (DHSS 1983) had called for more professional management of the NHS, and had been followed by a series of administrative and economic reforms of the health service that embodied a management efficiency logic. From the start of the 1990s, this effort involved introducing a limited market economics, in which district health authorities purchased the services they required from hospitals, ambulance services, and other health service providers on a contractual basis that supported competitive tendering (DOH 1989). The 'internal market' logic set forth a vision of good health care as measured by performance against numerical targets, and morally responsible health service organizations as those that could compete effectively with other providers on a price/performance basis. Information technology was seen as an important mechanism for instituting the desired ethical behaviours.

Within the ambulance services, the numerical targets took the form of response times to emergency calls. Thus how long ambulances took to arrive at emergency scenes was the determinant of good care, and services were compared in terms of their performance to the national targets (at that time, $50 \%$ of responses in 8 minutes and $95 \%$ of responses in 14/19 minutes in urban/rural areas). Although these performance standards - called ORCON (Operational Research Consultancy) standards - had been in effect for some years, the internal market initiative and the introduction of professional management practices into the NHS gave them prominence.

The LASCAD project (1990-92) was an attempt by the LAS to introduce information technology as a response to the Conservative government's modernization initiative. The aim was to introduce a highly innovative system that fully automated the command and control functions of the LAS - from receipt of an emergency call at the control centre, through decisions on which ambulance to allocate to the call, to mobilization of the appropriate resources to the incident. Call details would be captured online, tracking devices would be fitted to ambulances so that their locations could be monitored continually, and mobilization instructions would be passed via an electronic link from the control centre to either mobile data terminals in the vehicles or printers on ambulance stations. At the time, the core operational areas of the LAS - most notably the emergency staff - worked with pen and paper, supported by telephones and a radio system for maintaining contact between the control centre and ambulances attending emergency incidents. Thus, the LASCAD project was a significant break with established ways of working, which presented moral challenges for those involved.

\subsection{Data collection}

I collected the main body of data for this research between February 2000 and February 2001, when I was observing then current IS innovation efforts at the LAS. My

\footnotetext{
${ }^{4}$ Pollock (2005) provides a compelling account of how the British NHS has been progressively privatised since the early 1990s. Nevertheless, Government rhetoric generally maintains the illusion of free, universal access.
} 
aim was to examine how the organization was coping with the ongoing programme of modernization in the ambulance service - and the British health service more generally - in light of the issues encountered when the LASCAD system collapsed in 1992.

During the research period, I conducted 38 interviews of 60-150 minutes duration. These meetings involved staff from different hierarchical levels and functional groups, including board directors, departmental managers, members of the staff training unit, IT specialists, and quality assurance advisors. I asked each interviewee to comment on all of the IS innovation projects in which they had been involved, which in some cases included a discussion of efforts that had taken place during the 1980s. I attended 21 project meetings and 6 staff training sessions relating to the then current efforts, witnessing some obvious tensions among the parties involved, the root of which became clearer to me as my research progressed, as discussed earlier. I spent another 75 hours observing front line operations, both in the LAS control room and at emergency scenes, this time using the opportunities to question staff as they did their work. I drew upon several documentation sources relating to current and past IS projects, including service and IT strategies, project plans and meeting minutes. Finally, I referred to public inquiry reports into the performance of the LAS (HOCSCOH 1995; Page et al. 1993)

\section{ANALYSIS}

This section addresses the way that different groups of LAS staff responded to the moral dilemmas presented by the LASCAD system. Specifically, I examine how the Government's modernization initiative challenged the established ethical behaviours by trying to replace individually stylized views of what it meant to provide a caring service with a universalistic view based on management efficiency logic. In effect, an important moral problematization for staff involved in the modernization initiative concerned the question of how one judges the quality of care provided by the ambulance service. Moreover, in the dynamics of forming their personalized moral stances, emotions were strongly implicated in how individuals came to care for their own and others' lives.

\subsection{The established ethical behaviours}

Some members of the LAS viewed caring for the patient as establishing empathy gaining an understanding of the emotions of the patient and the caller (who can be different people), which may be anxiety, frustration, anger, guilt, or other feelings. Call takers, in particular, would subscribe to this view, since they are in no position to give "hands on" care to the patient, but do have to ensure that $\mathrm{s} / \mathrm{he}$ is as comfortable as possible while awaiting the ambulance. Often, they have to administer medical procedures over the telephone - for example, cardio-pulmonary resuscitation (CPR) or childbirth instructions - when the circumstances of the call are particularly emotionally charged. Moreover, they have to establish that the situation is safe for the crew to enter when they arrive, and this involves getting vital information from the caller, whom they have to ensure is calm enough to provide it. In these situations, they would draw not just on clinical knowledge but also on their own life experiences - as a pregnant woman, a parent of a sick child, a carer for an elderly relative, or whatever - to deal with the call.

Other members of the service viewed the outcome achieved by the patient as the key determinant of performance. For example, vehicle crews would argue that the medical procedures they perform at the scene or on the way to hospital contribute to these outcomes, and these procedures implicate cognitive and emotional skills that are not measured by a response time target. Indeed, ambulance services are generally not aware of the outcomes achieved by their patients, since these details form part of the 
performance statistics of the hospital to which the patient is conveyed. Thus this caring work is not visible (Bowker and Leigh Star 1999) in the performance statistics of ambulance services, causing some to argue that they are assessed as cab drivers, being judged to perform well if they take you where you want to go quickly and safely.

Sector teams (comprising a duty manager, radio operator and telephone dispatcher) acted as the interface between the call takers and the vehicle crews, with responsibility for allocating ambulances to calls in the various geographical divisions or sectors into which London was divided for resource management purposes. Since they had no contact with the caller or the patient, their contribution to patient care rested in maintaining the resource distribution as accurately and effectively as possible under the control of the duty manager. Nevertheless, in this aspect of the job as well, emotions came into play. In particular, in the early 1990s, the ambulance service officially addressed all calls in the order in which they were received, irrespective of the seriousness of the patient's condition. However, at busy times, when calls were backed up awaiting the availability of an ambulance, the "first in, first out" code of ordering was regularly breached. Allocators determined priorities for resource usage in terms of the perceived needs of each patient, and emotions were a key influence on how these assessments were made. For example, calls to attend a sick baby typically received a high priority, breaching the official code of ordering, but also revealing a decision making process in which a general human disposition to show affection for very young children carried considerable weight, irrespective of the seriousness of the child's condition. Thus, even in situations where the operators had no contact with members of the public, their ethical behaviours were strongly influenced by their dispositions and affections, pragmatically constructed according to their life experiences.

Moreover, when a major incident - such as a train crash or motorway accident occurs, commentators who commend the performance of the ambulance service always emphasize the types of caring work outlined above as indicative of good performance. At particularly intense and high profile moments, it seems, it is socially acceptable to mention caring in any of its cognitive and emotional dimensions, but at other times it is reduced to an economic measure where caring is a number. In short, by heightening the attention paid to ORCON standards, the internal market initiative devalued further the 'invisible' work (Bowker and Leigh Star 1999) that had always been done by the ambulance services.

\subsubsection{Striving to transform their lives}

Within the established ethics, staff recognized their responsibilities to patients through an articulated and accepted rule of their community, which required them to use their knowledge and skills to respond to every call for help, and to develop empathy with the patient using their experience of similar situations. In this way, each individual's 'mode of subjection' to their moral responsibilities was in large part a personal one, a self-styled mode of caring for themselves and others, more so than a quasi-juridical disciplinary mode mandated by ORCON standards. For example, staff varied their conversations with callers and patients according to how they judged their success in achieving desired outcomes, subscribing to 'techniques of the self' that required them not to respond to the anger, stress or frustration of members of the public with a response in kind. Clearly their personal capacities and professional and life experiences were important aspects in how well they maintained this position while trying to carry out the necessary procedures, and also in how long it took them to do so. Moreover, how stressed or otherwise they felt during and after the call was a personal monitor on their efforts at self-discipline. 
For all of the groups discussed above a key goal was to be recognized for their medical knowledge - to shake off popular images of themselves as a call centre, a group of 'glorified porters' (Radio Four 2002) or even a branch of social services. Their desire was to be seen as 'paramedics' - in the broad sense of 'supporting the work of doctors' - and they strove to achieve this goal in a number of ways, from undertaking formal training to making the most of opportunities to learn through experience. Unlike the scripted interactions that are commonplace when dealing with a call centre, staff had significant freedom to stylize their conversations with callers. Moreover, vehicle crews were always keen to attend major emergencies where opportunities might arise to use their specialist skills and equipment.

\subsubsection{The central role of allocation boxes}

In the established system that operated prior to LASCAD, staff subscribed to a substantive moral position that was historically and culturally constituted, value-laden and emotionally charged. Central to enacting this position were the allocation boxes of the 3 duty managers (or allocators) in the control centre. Using a system of slotted holes, coloured tags, and differently coloured forms, the allocators maintained in their boxes a profile of the resource usage in the different sectors of London for which they were responsible. Each member of the operational staff had a part to play in keeping these forms as complete and current as possible.

Specifically, call takers recorded initial incident details on the forms, which were then passed to the relevant sector via a conveyor belt and manual sorting process. Allocators added details of the resources assigned to the call, and then dispatchers used the forms to issue instructions to vehicle crews. Radio operators added further details when crews called in their availability. When new information came to light (say, police called to scene), further updates occurred. The coloured tags were updated at the start of each shift, when ambulance stations notified allocators of the crews on duty in their sectors, and if a crew was temporarily reassigned because an allocator had spare resources, again the contents of the relevant allocation box were updated.

Each form (or set of related forms) was intended to tell the story of an incident, and the boxes were filled with and emptied of them as the incidents unfolded. Everyone knew the part they had to play, in terms of both the individual freedoms they had within this system and the limits it imposed on them as a participant in a joint effort to provide a caring service. If the network broke down, patients' lives might be at risk, but so also might the safety of the crews. The combination of attending to patient care and crew safety formed the overarching goal of the operators' ethical subject - to foster the health of the nation, which meant caring for themselves as well as for others.

This was not a straightforward goal, for it involved conflicting concerns - as when a patient needs urgent assistance and the scene is dangerous, say, because an assailant is still present. Getting all of the relevant information from the caller, making sure it was passed through to the allocator - and then on to the vehicle crew - as soon as it became available, and notifying changes as they happened were vital tasks. Anxiety was always free-floating in this job (Giddens 1991), but the allocation boxes and the well established routines that had developed around them acted against the fixing of it. They were a visible symbol of power/knowledge relations that held together a fragile moral order and an unstable social one.

\subsection{A new moral vision}

The LASCAD project disturbed this discourse by seeking to replace the paper artefact with information technology. The new system was inscribed with particular 
notions of ethically responsible behaviour for LAS staff, which subscribed to the moral problematization instituted by government ministers and health service officials, and enshrined in the response time targets, that a caring and responsible ambulance service was one that provided a speedy response. Thus the prescribed working practices for all staff were geared to this goal.

The aim was to save vital minutes, which were 'lost' both when assigning resources (owing to the slow paper interface linking the work of call takers and allocators), and when dispatching resources (since crews again transcribed the call details before going mobile). In addition, using tracking devices on vehicles, LASCAD sought to determine more accurately the locations of vehicle crews, replacing the existing method in which their exact positions were only known when they made contact with the control room. On this point, when crews were available but mobile (typically, returning to their stations to await further work), an allocator needing to assign resources to a new call had to estimate their locations to decide who was nearest to the incident - decisions often contested between control room staff and crews.

Within the prescribed working practices, call takers would not only take details of emergency incidents from callers, but also - within parameters determined by senior managers and under the control of the system - allocate ambulances to the calls they received. This move would be possible since the current resource distribution profile, rather than being held in allocators' boxes, would be maintained by the LASCAD system. On 26 and 27 October 1992 the parameter in force was that the nearest resource was less than 11 minutes from the scene (Page et al. 1993). The allocators would make the more complex resourcing decisions, and would no longer sit on the sectors maintaining resource utilization details, but would stand back behind their teams and manage by walking about - a popular idea in the management literature of the time (Peters and Austin 1985).

Radio operators' and telephone dispatchers workloads would reduce since voice communications with vehicle crews would take place in exceptional circumstances only, replaced by mobile data terminals in vehicles and printers on ambulance stations for passing instructions. Vehicle crews would adopt new methods of working, including accepting text instructions from the control room in place of voice communications, and pressing status buttons in their vehicles to tell control room staff what they were doing for example, on scene, en route to hospital, available. Moreover, control room staff would track their precise locations via aerials fitted to their vehicles. In effect, vehicle crews would subscribe to a disciplinary regime (Foucault 1977) that used information technology to regulate and monitor their activities, making their actions transparent to their control room colleagues.

However, the established ways that these individuals made themselves the subject of a guiding principle requiring the ambulance service to be a freely available, effective emergency health service for all who need it implicated ethical behaviours that did not reduce to a response time target. Their concerns about the simplistic logic of ORCON standards is captured in the following comment (Nicholl et al. 2001, p.16):

If you get there in 8 minutes and the patient dies you've succeeded, but if you get there in 9 minutes and the patient lives you've failed (Director of Corporate Resources, Ambulance Service).

In focusing exclusively on the need to meet ORCON standards, the LASCAD system challenged established practices along a number of key emotional dimensions. As discussed already, it subsumed the emotions of caring in favour of a rationalistic measure of response time efficiency, which denied the range of human capacities that ambulance staff brought to their work. As discussed next, it set the scene for heightened levels of anxiety by replacing the allocation box method of resource management with a 
technological artefact which threatened workers' moral sense of who and what they were in their present situation.

\subsection{Implementing the moral vision}

During the first nine months of 1992, efforts to install and test the new hardware and software involved a stream of negotiations and trials of strength among LAS staff, their managers, and the LASCAD system. Continuing problems with the system, changes made to it "on the fly" (Page et al. 1993, p.30), and an increased workload for staff during parallel running hindered the process of enrolling support for the new ways of working from a reluctant, and sometimes militant, workforce:

There was no change control ... Corners had been cut everywhere. (Testing team leader ${ }^{5}$ ).

Workload doubled ... because you were running the two systems in tandem. (Radio operator).

It was so difficult to keep track of, quite apart from the fact that West Ham ambulance station ... never appeared on [the tracking system], and neither did any of [its] vehicles for some considerable time ... - apparently a victim of thermo-nuclear attack! (Sector team member).

And all the time we were trying to prepare the training the system was changing ... you couldn't keep up, you just could not keep up ... things were changing almost minute by minute, certainly hour by hour and, most definitely, day by day, and no one ever knew. (Training manager).

Throughout parallel running of the system, reliance on the allocation boxes endured. Far from resolving disputes about allocation decisions, new and more serious conflicts arose with LASCAD. In particular, the well established system in which allocators had learnt spatially to match and collate forms when multiple calls were received for the same incident - as may happen when a road traffic accident occurs - proved more difficult to enact using the windows of a graphical user interface. As a result, there were many instances where several crews were sent to the same call and several instances where no crew was sent. Attempts to impose the prescribed behaviours, such as taking away an allocator's box, strengthened allegiances to the established ethical regime:

... but we was desperate to hang on to [paper] because it was our means of knowing what we were sending vehicles on, or what vehicles we had. And one day [the chief executive] just, he just walked into Control and he said "get rid of that bloody paper", and he just grabbed hold of the box and walked, walked away with it ... and left those people with just no backup at all. (Allocator).

And not least of the worries was about the printers themselves because ... calls ... wouldn't print out. And for those who were relying more on the paper side of things than the screen, they didn't react to something they didn't get ... so we were losing calls. And then to take away [the boxes] as well ... if you've been used to paper, it's like taking a child's comforter away - it doesn't matter whether they need it or not, they feel happier with it. (Control room manager).

As parallel running continued, design loopholes were uncovered. For example, staff could allocate empty ambulances to emergency calls, but might find that ambulances with a crew assigned were deemed unavailable. The system response to these situations was to print exception reports on a dot matrix printer, adding to the din in a crowded, emotionally charged control room, in which operators sometimes crawled under their desks to reduce noise to a level where they could give dispatch instructions.

\footnotetext{
${ }^{5}$ Attributions refer to roles the commentators undertook during the LASCAD implementation rather than their roles when this research was undertaken.
} 
Further problems arose because both duty managers and call takers were able to allocate ambulances, but the mechanism for determining who dealt with which calls was easily bypassed. Numerous spurious exception reports were produced:

So while we were running in tandem, we used to knock [the exceptions] off ... there was a certain way you were supposed to do that ... but that was often impossible because you'd given [the call] to a vehicle [the system] didn't believe existed. So you used to have to con the computer, and we found ways to do that. (Sector team member).

As problems mounted, confusion and conflict broke out among staff, but thus were opportunities revealed to vent frustration, by subverting the operation of the system: And we was getting abused by vehicle crew staff - "you don't bloody well know what you're doing" - ... [because] sometimes you'd sent 2 or 3 vehicles to the same call, and sometimes you hadn't even sent a vehicle to a call, because you didn't know whether you'd done it or not. (Allocator).

Then some, some operational staff tried to sabotage it, so they'd stick screwdrivers in the aerials and whatever. (Dispatcher).

$\ldots$ and there was all sorts of mayhem going on with regards to trying not to use those data transmission terminals, especially after we had implemented it. ... They worked out very early on that all they had to do was give you slightly duff information and then you wouldn't have an upto-date system anyway. And what the system did then was to give you lots of exception reports, and we were just inundated by exception reports ... all of these things were just coming up by the screenload - pages and pages and pages of them. (Control room manager).

While voice communications continued, and hence the paper system endured, such subversions could be addressed with talk, albeit an increasingly angry talk among the staff concerned. Allocation errors in the control room played through onto the streets, with vehicle crews receiving increasingly angry responses from members of the public as wait times increased.

Finally, managers addressed what they could see as the points of resistance; they rearranged the control room layout on 26 October 1992 as the system went live panLondon - a move from the parallel running mode of operation in three sector teams. As the control room layout was reconfigured, the familiar team structures were disbanded, the allocation boxes were removed, and voice communications were replaced by electronic data transfer. In the control room, at least, managers had blocked the ways out of using the system, but they had enrolled no more than a hostage to fortune, for they had also blocked the escape routes that staff might have used to address the problems that occurred. Control room staff could not find a way to manage as the less visible points of resistance came into play - vehicle crews on the road and the system itself - and so the vision became 'a nightmare'.

People kept ringing in "where's the ambulance, where's the ambulance?" "Shit, I thought I'd sent the ambulance". "No, you haven't sent the ambulance". And all these calls ... the screens were just filling up and filling up with calls, and you couldn't keep on top of what you'd sent to what. And this thing over here [the printer] was just spewing. It was just pumping out!

And then some people would take [the call] on paper because the screen had locked up, and some people would take it on the computer, and some people wanted to assign vehicles and you're saying "stop assigning vehicles, only the sector, the sector desk can assign the vehicles". And then some people would just play with the map, just to look at vehicles going round, up and down roads and [nothing said]. But it got to the stage where so many people were doing so many different things that it was starting to get slower and slower and slower ...

And then, of course, obviously, everything had happened overnight because that's when it, that's when it, it crashed, eventually ... I, I remember waking up when the news was on. And that's 
when they said about, you know, "the London Ambulance Service has crashed" and "it's chaos, people aren't getting ambulances and people are dying and being killed and [nothing said]".

And then the next thing you saw on the news was that John Wilby had resigned - as the chief executive of the London Ambulance Service. (To which your reaction was, I asked). Oh, everybody was just, like, elated. It was like a whole burden, a whole weight, had been lifted off your shoulders, 'cause everyone in the Control had just gone back to the old paper system, just taking calls on paper, sending them to the sector. Crews were working - with the Control - and everyone was just [nothing said].

But that morning of the crash, I mean when people were just, just coming on and off duty in tears - people that came off duty were just like in floods of tears - it was awful, it really was. It was like it was a nightmare - an absolute nightmare. (Dispatcher).

In this situation, as in others where a group has experienced an emergency (for example, Weick 1993), there were a range of responses. The above commentary reveals that some cases of sabotage did occur, in which staff struck back at the threatening object - the technology - but it also highlights other ways in which they experienced the step change in anxiety associated with fear or panic. For example, efforts were made by many to persist with the new ways of working even while breakdowns were occurring, in part at least because they judged that alternative options were closed off. Others found pieces of paper and tried to revert to the manual system as problems mounted, while some were alienated to the point of making a partial detachment from what was happening, remaining engaged only insofar as they watched the progress of vehicles as recorded by the mapping system. Deprived of voice communications in an operation that historically had addressed every task with talk, the crippling effects and sense of helplessness were acute in some cases. Unsurprisingly, in the control room, which was both the heart of the operation and a confined space in which many were enclosed, panic spread quickly.

Semi-manual operations were resumed in the afternoon of 27 October. The chief executive resigned the same day and was immediately replaced by his successor, who had been placed on standby in advance (Channel Four Television 1996). Allegations that up to 20 patients had died while waiting for ambulances (Guardian 1992; Independent 1992) led the regional health authority to announce a public inquiry within days of implementation.

In semi-manual mode, use of the call taking subsystem continued for several more days, as did mobilization of resources direct to station printers or mobile data terminals, but the manual systems for tracking and allocating those resources were reinstated.

Meanwhile, a small programming bug was at work filling memory in the file server, so that ultimately the system locked up completely a little after 2am on 4 November 1992. Attempts to restart the system failed, at which point a full withdrawal occurred and the manual operations of the established ethical regime were resumed.

\section{DISCUSSION}

Although the previous section emphasizes the attachments of control room staff to the allocation box method of resource management, crucial to these attachments was the knowledge that vehicle crews also accepted this method. Indeed, more than a decade after LASCAD, all IT developments at the LAS had left the allocation boxes undisturbed, and the crews' attunements with this method of resource management was one of the most compelling reasons for retaining it. Central to this enduring acceptance was the issue of how much personal discretion the allocation boxes permitted in the work practices of staff - in particular, the level at which they allowed the work of vehicle crews to be scrutinized. In this case, staff did not find the disciplinary regime 
oppressive because the granularity of work monitoring (Bowker and Leigh Star 1999) was not significant. Indeed, once a radio or telephone dispatcher had mobilized a crew to an emergency incident, there was no further automatic time stamping of work until the crew was given the next call. Instead, the times the crew arrived on scene, got to hospital, completed handover of the patient, and subsequently called up "green" (available) at the hospital were recorded after the event on a patient report form (PRF), which the crew completed. PRFs were then processed by a batch system to determine the response times against ORCON standards. Thus,

[the PRF] is a work of fiction - some of them could be up for the Booker prize ${ }^{6}$ (Control room support manager).

In the manual system, crews had scope to negotiate their availability for work. How they were feeling about the demands of the job at any given time was extremely significant in such negotiations, and many things affected these feelings. So, if crews had just dealt with a couple of "crap calls" (their term for abuse of the service), or there was a poor industrial relations climate, cycle times would lengthen. Crews would take time out at the hospital before calling up available. How they constructed the PRF in these circumstances varied:

It has been suggested to me that some staff deliberately record a time that takes their response outside ORCON ... because they are pissed off with the LAS ... [Others] usually don't change the response time. They are more likely to change the time on scene - there's no way of estimating how long that might be. (Service development officer).

Returning to the research question on the nature and role of emotions in this case, we find that how members of staff came to care for patients was intimately related with their own feelings about how the ambulance service and its users were caring for them. In effect, their emotions revealed not just their personal dispositions in relation to a particular call for help, but also where they stood on a much broader range of ethical issues - issues that were denied legitimacy within the LASCAD system. The remainder of this section addresses these concerns.

\subsection{Emotions revealing the broader ethical issues}

The moral prescription inscribed within the LASCAD system was introduced at a time of poor industrial relations within the LAS, following a bitter national dispute during the winter of 1989-90 about pay and working conditions within the ambulance services. Although this dispute was countrywide, it was particularly pronounced in London, where the cost of living is higher and the social problems dealt with by the ambulance service are generally greater than elsewhere in the UK. Adding to London's social problems, crime rates and traffic congestion in the capital are particularly pronounced, and so too are the effects of these issues - inappropriate use of the ambulance service, dangerous working conditions for vehicle crews, and difficulties in navigating traffic at speed.

Moreover, in the early 1990s, ORCON standards laid down that all emergency calls to the ambulance services had equal priority, so that a patient in cardiac arrest (who was immediately life-threatened) received the same response as a patient with a minor injury. In the former case, clinical evidence suggests that 8 minutes is the maximum response time available to prevent premature death, in the latter case experience suggests that an emergency response may not be required at all. Ambulance crews

\footnotetext{
${ }^{6}$ The Booker prize is a prestigious award for works of fiction.
} 
became increasingly frustrated when called to non-emergency incidents, and their ethical behaviours were tested further when the service was used by hoax callers, patients without a general practitioner, or those with conditions perceived to be within the remit of social services, for example, mental health problems and alcoholism.

At that time, some members of the LAS staff were employing unofficial ways of responding to emergency calls - ways designed to tackle these issues. Vehicle crews and control room staff were already using tacit knowledge not inscribed within the LASCAD system to make clinical judgements about how to prioritize emergency incidents. Keen to shake off their image as 'glorified porters' (Radio Four 2002), staff welcomed opportunities to demonstrate their medical knowledge and skills. Moreover, they often had well-founded suspicions that a call would make inappropriate use of their resources, for example, because they could identify the addresses of frequent abusers of the service.

In general, though, a concern for patient care meant that crews responded quickly and caringly during each call cycle up to the point when the patient was handed over at hospital, but how long they waited at hospital before reporting "green" was very variable. Compelling among the possible scenarios for constructing the PRF to account for "lost" time is the one where crews reached patients within the ORCON standard of 8 or 14 minutes and then reported that they did not in order to express anger or frustration with their managers. In this way, they remained authentic to their feelings about patient care, but faked it in the performance figures of the LAS, which might then attract public criticism of their managers and draw attention to staff concerns (Ashforth and Tomiuk 2000).

Of course, crews were aware as they took a break at hospitals that other calls were coming into the control room that needed emergency responses, but their ambivalence to their work situations manifested itself in vacillation (Pratt and Doucet 2000). Indeed, crews knew that staff in the control room would give them an official break when they could. Equally, control room staff knew that crews took unofficial breaks, even though the allocation box method of resource management did not allow them to know precisely when this was happening. At the heart of this conflict lay the issue that vehicle crews felt their concerns were marginalized within the established work regime, in which their control room colleagues occupied the vast majority of managerial positions. As a subjugated group (Foucault 1980) within the LAS, crews experienced the doubleness and ambiguity of being a member of a community of practice and yet marginalized within it - an experience which has been referred to as inhabiting a 'borderland' (Bowker and Leigh Star 1999). So, on the one hand, the crews accepted their moral responsibilities to patients, and the need to make a speedy response, particularly to life-threatened patients. On the other hand, they resisted a disciplinary regime that would make transparent those aspects of their work that contribute to a narrowly defined numerical target, while rendering invisible other aspects of caring work and the abuses they suffered while engaging in it.

While crews take a break at hospitals, their resistance to transparency manifests itself in the view that they have completed a job satisfactorily - they have handed over a patient assigned to their care; the patients who are now calling in are not their patients yet. Nevertheless, as they wait, one of them listens to their radio, and if they hear a general broadcast about a major incident - such as a rail crash - they offer up immediately. Indeed, 'they moan like hell if you don't send them' (control room support manager) because attending such incidents is for many the "real work" of the ambulance service. When the emergency need is clear, caring for others becomes a paramount concern. 
While social scientists do not rule out the possibility of developing coherent selves in a borderland, they also address the damage that can result from the ambiguity and suffering associated with such an identity. Several authors employ the term 'monsters' to refer to the being that is created when the legitimacy of multiplicity is denied - when an attempt is made to derive a pure, but illusory, system of categories into which each of us can be positioned without anomaly (Bowker and Leigh Star 1999). Despite their limitations, the allocation boxes left more scope for the workarounds, intuitions and emotions associated with multiplicity than did the technology that replaced them.

\subsection{How LASCAD denied the legitimacy of key issues}

The case reveals that existing, even apparently latent, conflicts and emotions may surface or heighten when IS innovation is attempted. In the LASCAD case, these subjugated knowledges and emotions emerged during efforts to achieve cultural change of the LAS through the use of ICTs inscribed with government-driven efficiency logic. The LASCAD system countered established ethical behaviours, posing moral dilemmas and challenges for those involved. It changed the level of granularity of work monitoring because it attempted to "know" what vehicle crews were doing at all times. Crew staff could no longer negotiate their availability for work - they could not judge when to take a break nor could they construct their PRFs accordingly. The system was tracking their locations, they were required to press buttons in their vehicles to notify their current activity, and all the while LASCAD was time stamping their work. In some cases, their feelings and responses to them changed from ambivalence and vacillation to negativity and sabotage (Pratt and Doucet 2000). Moreover, control room staff could not work around the issues arising without their allocation boxes. During the LASCAD implementation, rather than using a combination of paper, experience, and "gut feel" to tell them what crews were doing, sector staff had a computer system that not only had no tolerance of multiplicity but no expectation of it.

However, the LASCAD system provided new possibilities for some call takers opportunities to allocate ambulances if they were located less than 11 minutes drive from the scene. Call takers embraced this attempt to replace a paper artefact with a technological one until it became apparent that this way of organizing presented serious problems. For the LASCAD implementation did not just redistribute responsibility for ambulance allocation; it no longer maintained the boundaries - the sectors or divisions within which each allocator and vehicle crew worked. Members of the control room were now working pan-London, allocating ambulances in areas they did not know, and drawing as if on a pool of resources rather than on the specific ones allocated to each sector. They could neither fully gauge the implications of their decisions nor adequately grasp the resource utilization pattern across the 620 square miles of London served by the LAS. Since time from scene, as determined by the system, was now the criterion affecting allocation decisions, crews were sometimes asked to respond a long way from their home station, which was not welcomed near end of shift. Emotions ran very high for 36 hours; then the allocation boxes were reinstated. Call takers continued to use the system for a few more days - simply to record call details online, which sector staff could then print and deposit in their boxes - but from 4 November 1992 even the paper forms were being handwritten once more.

Overall, LASCAD sought to achieve technical and administrative efficiency of the LAS, consistent with the government's agenda for reform of the NHS, but in reducing caring to a number it had a dehumanizing effect. In the ambulance services, response time targets are still at the heart of determining quality of service, and so caring work continues to be constituted in narrow terms. Moreover, recent anecdotal evidence from 
patients and health service staff suggests that targets may have endangered the lives they were intended to save. For example, vehicle crews have been waiting at hospitals not because they were taking unofficial break time, but because hospital staff were unable to complete the handover of patients (Anglia Television 2005). Faced with a shortage of beds and trolleys - on which emergency cases could wait to see a doctorpatients were left outside the hospital doors in the back of an ambulance, preventing vehicle crews from attending further calls, sometimes for several hours. Indeed, commentators allege (ibid.) that as accident and emergency units struggle to meet their 4-hour target for patient waiting times, hospital staff delay registration of emergency cases because the clock does not start ticking on their target while patients are still in the care of the ambulance service.

\section{CONCLUSIONS}

In this paper I have explored the nature and role of emotions in IS innovation, addressing how members of the LAS constituted the nature of their patient care role and how the deployment of ICTs disrupted the fragile and unstable moral and social order. Drawing from the theoretical work of Michel Foucault, and influenced by ideas from contemporary thinking about the sociology of organization (Albrow 1997; Bowker and Leigh Star 1999; Fineman 2000b), I have argued for an understanding of emotions as a constituent aspect of individuals' moral conduct. Rather than creating an opposition between rationality and emotionality, which too easily invites an effort to cure and ultimately rationalize affections, I argue that emotions are always implicated in our lived experiences, crucially influencing how we come to our beliefs about what is good or bad, right or wrong.

This view of what it means to behave ethically is not only opposed to Kantian notions of ethics based on an individual, autonomous, moral-rational agent but also to stereotypical notions of emotions as associated with gender - 'rational man' and 'emotional' (or irrational) woman (Meyerson 2000; Mumby and Putnam 1992). In Foucault's double bottom-up contextualist view (Flyvbjerg 1998), there are no a priori categories that pre-determine how particular actors will behave or who shall be suppressed or marginalized. Rather, these issues are situational and hence are revealed as part of a study. In short, Foucault's perspective on the ethical subject can provide explanatory potential for understanding any particular instance of IS innovation, and an opportunity for examining why actors seek to sustain certain affections, moods and dispositions while attempting to drive away others, which nevertheless remain lurking.

In the LASCAD case, the emotionally charged behaviours revealed where members of staff stood on a broad range of ethical issues. These issues included the need to prioritize emergency calls rather than adhering to a "first in, first out" rule of ordering; the role they desired to fulfill for the general public - as paramedics not porters; and the consequences of implementing Government policy, for example, on pay and working conditions, and on increasing levels of care in the community. This analysis suggests the following implications for IS research and professional practice.

First, a large body of literature has focused on the factors that contribute to acceptance of, or resistance to, information technology. In the technical/rational tradition of IS research, such models have sought to provide the best predictors of ICT adoption or elicit the factors contributing to user resistance. Examples include the Technology Acceptance Model (TAM) and various extensions to it (Davis 1989; Gefen and Straub 1997; Venkatesh et al. 2003), and Lapointe and Rivard's (2005) multilevel model of resistance to IT implementation. In general, emotions do not have a (substantive) role in this research tradition. When mentioned, they are seen as indicators 
only of the presence of a more important cognitive factor - for example, anxiety indicating a lack of perceived ease of use in TAM.

Furthermore, in the socio-technical tradition of IS research, emotions tend to be subsumed within a discussion of the political processes surrounding IS innovation. Thus, their role is often seen as indicating self-interest on the part of participants in the innovation efforts - for example, concerns about loss of status or power in an organization (Markus 1983). Some researchers suggest remedies to break down the accompanying defensive processes, say, the use of transitional objects - entities that provide temporary emotional support during necessary organizational change (Wastell 1999).

In this paper, I suggest an alternative approach. Rather than assuming that emotionally charged behaviours are simply indicative of more important cognitive concerns, or a form of resistance to change that may be pathological, I adopt the view that such behaviours are the most relevant aspect of a substantive moral stance (Foucault 1984). Thus, the nature and role of emotions deserve analytical attention in their own right. Indeed, individuals' dispositions and affections may suggest legitimate directions for an organization rather than being disruptive behaviours that should be suppressed. For example, within the ambulance service, the need to prioritize emergency calls was acknowledged in 1996 by a government-sponsored review of ambulance performance standards (Chapman 1996). The review team recommended that UK ambulance services adopted priority dispatch systems, in which resources are dispatched to emergency calls in a priority order depending on the criticality of the patient's clinical need. Moreover, in concluding that calls to children under two years of age - regardless of perceived clinical need - should be given the highest of the three designated priorities, it cited as one reason that public perception would demand it. These systems became fully effective in 2001, and mark a shift in the prescribed ethics for ambulance services, the roots of which may be traced in the alternative, empathetically informed conduct that prevailed at an earlier time and challenged the moral code inscribed in the LASCAD system.

Second, this research can be progressed on a number of fronts. Further work may address the nature and role of affections in episodes of IS innovation in other work situations, organizational settings or cultural contexts. However, comparative analyses of affective differences between, for example, emergency and non-emergency work, public and private sector operations, and British and other national contexts, are just one type of agenda. Others include progressing work on ethics and gender relations (Adam 2005; Alvesson and Billing 1997; Knights and Murray 1994), including alternative notions of the role of emotions in ethical behaviour, and analyses of how environments become gendered and hence convey particular notions of emotional acceptability in professional roles and ICTs. Indeed, once affections are acknowledged as deserving attention in their own right, such work can take as many directions as analyses of cognitive behaviours, and may also explore the relationship between rationality and emotionality (Avgerou and McGrath 2005).

Moreover, public awareness is lacking of IS innovations and related issues in the public services, even though they have the potential to affect the lives of all citizens. IS research tends to focus on the deployment and use of ICTs in organizations, whether business enterprises or public sector organizations. Thus little work has been done to address citizens' use of and reactions to particular IS innovations or even their lack of awareness of them. Further research could usefully explore this area, with a view to disseminating the results widely enough to reach the public at large rather than just academic and/or practitioner audiences. 
Finally, we need to reconsider our illusory ethics that human experience can be understood from a position of emotional detachment (Meyerson 2000). LAS staff subscribed to a number of different moral stances about how to care for patients, but a common thread was the rejection of a position based on rationality and detachment for one based on empathy and engagement. The introduction of ICTs to rationalize operations delegitimated such engagement, and heightened the tensions thus created by inhibiting verbal communication among staff with disastrous consequences. These findings suggest that notions of the rational, detached actor are very suspect. That such a model of human behaviour is alleged to persist in so many business and professional enterprises would seem to have more to do with performance systems that value and reward such behaviour than with an exercise of freedom by the individuals concerned. In effect, such mechanisms are a constraint on peoples' capacities to act, frequently encouraging them to conceal or deny large parts of themselves, often in an effort to gain social acceptance (Meyerson 2000). However, beneath the surface much stress, anxiety and even burnout may exist, which individuals in many organizations feel unwilling to acknowledge because prevailing norms suggest that it would be a sign of weakness.

\section{REFERENCES}

Adam, A. (2005). Gender, Ethics and Information Technology. Basingstoke: Palgrave Macmillan.

Albrow, M. (1997). Do Organizations Have Feelings? London: Routledge.

Alexander, J., Giesen, B., Munch, R. and Smelser, N.J. (1992). The Micro-Macro Link. Berkeley, California: University of California Press.

Alvesson, M. and Billing, Y.D. (1997). Understanding Gender and Organizations. London: Sage.

Alvesson, M. and Deetz, S. (2000). Doing Critical Management Research. London: Sage.

Anglia Television. (2005). Why are we waiting?, Tonight with Trevor McDonald. 17 January.

Ashforth, B. and Tomiuk, M. (2000). Emotional labour and authenticity: Views from service agents. In Emotion in Organizations, Fineman, S. (ed.), London: Sage, pp. 184-203.

Avgerou, C. (2000). Information systems: What sort of science is it? Omega, 28, pp. 567-579.

Avgerou, C. (2002). Information Systems and Global Diversity. Oxford: Oxford University Press.

Avgerou, C. and McGrath, K. (2005). Rationalities and emotions in IS innovation. In Handbook of Information Systems Research: Critical Perspectives on Information Systems Design, Implementation and Use, Howcroft, D. and Trauth, E. (eds.), Cheltenham: Edward Elgar, pp. 299-324.

Barrett, M. and Walsham, G. (1999). Electronic trading and work transformation in the London Insurance Market. Information Systems Research, 10(1), pp. 1-22.

Bell, F. and Adam, A. (2004). Whatever happened to information systems ethics?: Caught between the devil and the deep blue sea. In Information Systems Research: Relevant Theory and Informed Practice, Kaplan, B., Truex, D., Wastell, D., Wood-Harper, A.T. and DeGross, J. (eds.), Boston: Kluwer Academic, pp. 159-174.

Beynon-Davies, P. (1995). Information systems 'failure': The case of the London Ambulance Service's Computer Aided Despatch project. European Journal of Information Systems, 4, pp. 171-184. 
Bloomfield, B.P., Coombs, R., Knights, D. and Littler, D. (eds.). (1997). Information Technology and Organizations: Strategies, Networks, and Integration. Oxford: Oxford University Press.

Bowker, G.C. and Leigh Star, S. (1999). Sorting Things Out: Classification and its Consequences. Cambridge, Massachusetts: The MIT Press.

Brosnan, M. (1998). Technophobia: The Psychological Impact of Information Technology. London: Routledge.

Channel Four Television. (1996). Red Base One Four, Documentary series. November December.

Chapman, R. (1996). Review of Ambulance Performance Standards. London: Department of Health, July.

Ciborra, C. (2006). The mind or the heart? It depends on the (definition of) situation. Journal of Information Technology, forthcoming.

Ciborra, C.U. (2002). The Labyrinths of Information: Challenging the Wisdom of Systems. Oxford: Oxford University Press.

Ciborra, C.U. and Associates (eds.). (2000). From Control to Drift. Oxford: Oxford University Press.

Davis, F. (1989). Perceived usefulness, perceived ease of use, and user acceptance of information technology. MIS Quarterly, 13(3), pp. 319-340.

DeMarco, T. (1979). Structured Specification of Business Systems. Englewood Cliffs: Prentice Hall.

DHSS. (1983). Report of the NHS Management Inquiry. London: HMSO.

DOH. (1989). Working for Patients. London: HMSO.

Fineman, S. (ed.). (1993). Emotion in Organizations (1st ed.). London: Sage.

Fineman, S. (ed.). (2000a). Emotion in Organizations (2nd ed.). London: Sage.

Fineman, S. (2000b). Emotional arenas revisited. In Emotion in Organizations, Fineman, S. (ed.), London: Sage, pp. 1-24.

Flyvbjerg, B. (1998). Empowering civil society: Habermas, Foucault and the question of conflict. In Cities for Citizens, Douglas, M. and Friedmann, J. (eds.), New York: Wiley, pp. 185-211.

Foucault, M. (1971). Madness and Civilization. London: Routledge.

Foucault, M. (1973). The Birth of the Clinic. London: Tavistock.

Foucault, M. (1977). Discipline and Punish: The Birth of the Prison. London: Penguin.

Foucault, M. (1978). The Will to Knowledge: The History of Sexuality, volume 1. London: Penguin.

Foucault, M. (ed.). (1980). Power/Knowledge: Selected Interviews and Other Writings 1972-1977. New York: Prentice Hall.

Foucault, M. (1984). On the genealogy of ethics: An overview of work in progress. In The Foucault Reader: An Introduction to Foucault's Thought, Rabinow, P. (ed.), London: Penguin, pp. 340-372.

Foucault, M. (1985). The Use of Pleasure: The History of Sexuality, volume 2. London: Penguin.

Foucault, M. (1986). The Care of the Self: The History of Sexuality, volume 3. London: Penguin.

Franz, C. and Robey, D. (1984). An investigation of user-led system design: Rational and political perspectives. Communications of the ACM, 27(12), pp. 1202-1209.

Gagliardi, P. (1999). Exploring the aesthetic side of organizational life. In Studying Organizations, Clegg, S., Hardy, C. and Nord, W. (eds.), London: Sage. 
Gefen, D. and Straub, D. (1997). Gender differences in the perception and use of e-mail: An extension to the technology acceptance model. MIS Quarterly, 21(4), pp. 389-400.

Giddens, A. (1990). The Consequences of Modernity. Cambridge: Polity Press.

Giddens, A. (1991). Modernity and Self-Identity. Cambridge: Polity Press.

Guardian. (1992). Ambulance chief resigns. 29 October, p. 1.

Hochschild, A. (1979). Emotion work, feeling rules and social structure. American Journal of Sociology, 85(3), pp. 551-575.

Hochschild, A. (1983). The Managed Heart: Commercialization of Human Feeling. Berkeley, CA: University of California Press.

HOCSCOH. (1995). House of Commons Select Committee on Health Second Report London's Ambulance Service. London: HMSO, 12 June.

Huijer, M. (1999). The aesthetics of existence in the work of Michel Foucault. Philosophy and Social Criticism, 25(2), pp. 61-85.

Independent. (1992). Software failure 'may be behind ambulance crisis'. 30 October, p. 2.

Knights, D. and Murray, F. (1994). Managers Divided: Organisation Politics and Information Technology Management. Chichester: Wiley.

Knights, D., Noble, F. and Willmott, H. (1997). 'We should be total slaves to the business': Aligning information technology strategy - issues and evidence. In Information Technology and Organizations, Bloomfield, B.P., Coombs, R., Knights, D. and Littler, D. (eds.), Oxford: Oxford University Press, pp. 13-35.

Lapointe, L. and Rivard, S. (2005). A multilevel model of resistance to information technology implementation. MIS Quarterly, 29(3), pp. 461-491.

Lee, A.S. and Baskerville, R.L. (2003). Generalizing generalizability in information systems research. Information Systems Research, 14(3), pp. 221-243.

Markus, M.L. (1983). Power, politics and MIS implementation. Communications of the ACM, 26(6), pp. 430-445.

Markus, M.L. and Bjørn-Andersen, N. (1987). Power over users: Its exercise by system professionals. Communications of the ACM, 30(6), pp. 498-504.

Marx, K. and Engels, F. (1977[1888]). Manifesto of the Communist Party. Moscow: Progress Press.

Meyerson, D. (2000). If emotions were honoured: A cultural analysis. In Emotion in Organizations 2nd ed., Fineman, S. (ed.), London: Sage, pp. 167-183.

Mumby, D. and Putnam, L. (1992). The politics of emotion: A feminist reading of bounded emotionality. Academy of Management Review, 17, pp. 465-486.

Nicholl, J., Turner, J. and Martin, D. (2001). The Future of Ambulance Services in the United Kingdom: A Strategic Review of Options for the Future of Ambulance Services. London: Ambulance Services Association, June.

Oatley, K. and Jenkins, J. (1996). Understanding Emotions. Cambridge, Massachusetts: Blackwell.

Orlikowski, W.J. (2000). Using technology and constituting structures: A practice lens for studying technology in organizations. Organization Science, 11(4), pp. 404428.

Page, D., Williams, P. and Boyd, D. (1993). Report of the Inquiry into the London Ambulance Service. London: South West Thames Regional Health Authority, 25 February.

Peters, T. and Austin, T. (1985). A Passion for Excellence: The Leadership Difference. New York: Random House. 
Pettigrew, A. (1990). Longitudinal field research on change: Theory and practice. Organization Science, 1(3), pp. 267-291.

Picard, R. (1997). Affective Computing. Cambridge, Massachusetts: MIT Press. Pollock, A. (2005). NHS plc: The Privatisation of our Health Care. London: Verso.

Porter, M.E. and Millar, V.E. (1985). How information gives you competitive advantage. Harvard Business Review, 63(4), pp. 149-160.

Pratt, M. and Doucet, L. (2000). Ambivalent feelings in organizational relationships. In Emotion in Organizations, Fineman, S. (ed.), London: Sage, pp. 204-226.

Radio Four. (2002). Emergency. 15 July.

Silva, L. and Backhouse, J. (1997). Becoming part of the furniture: The institutionalization of information systems. In Information Systems and Qualitative Research, Lee, A.S., Liebenau, J. and DeGross, J.I. (eds.), London: Chapman and Hall, pp. 389-414.

Strati, A. (1999). Organization and Aesthetics. London: Sage.

Suchman, L. (1987). Plans and Situated Action. Cambridge: Cambridge University Press.

Taylor, F. (1911). Scientific Management. New York: Harper.

Trauth, E. and Jessup, L. (2000). Understanding computer-mediated discussions: Positivist and interpretive analyses of group support system use. MIS Quarterly, 24(1), pp. 43-79.

Trist, E., Higgins, G., Murray, H. and Pollock, A. (1963). Organisational Choice: Capabilities of Groups at the Coalface under Changing Technologies. London: Tavistock.

Venkatesh, V., Morris, M., Davis, G. and Davis, F. (2003). User acceptance of information technology: Toward a unified view. MIS Quarterly, 27(3), pp. 425478.

von Bertalanffy, L. (1968). General Systems Theory. New York: Braziller.

Walsham, G. (1993). Interpreting Information Systems in Organizations. Chichester: John Wiley.

Walsham, G. (1995). Interpretive case studies in IS research: Nature and method. European Journal of Information Systems, 4, pp. 74-81.

Walsham, G. (2001). Making a World of Difference: IT in a Global Context. Chichester: John Wiley.

Wastell, D. (1996). The fetish of technique: Methodology as a social defence. Information Systems Journal, 6, pp. 25-40.

Wastell, D. (1999). Learning dysfunctions in information systems development: Overcoming the social defences with transitional objects. MIS Quarterly, 23(4), pp. 581-600.

Wastell, D. (2003). Organizational discourse as a social defence: Taming the tiger of electronic government. In Global and Organizational Discourse about Information Technology, Wynn, E., Whitley, E., Myers, M. and DeGross, J.I. (eds.), Boston: Kluwer Academic, pp. 179-195.

Wastell, D. and Newman, M. (1996). Information systems design, stress and organisational change in the ambulance services: A tale of two cities. Accounting, Management and Information Technologies, 6(4), pp. 283-300.

Weber, M. (1947). Sociological categories of economic action. In Max Weber: The Theory of Social and Economic Organization, Parsons, T. (ed.), New York: The Free Press, pp. 158-323.

Weber, M. (1978). Economy and Society. Berkeley, CA: University of California Press. 
Weick, K. (1993). The collapse of sensemaking in organizations: The Mann Gulch disaster. Administrative Science Quarterly, 38(4), pp. 628-652.

Williamson, O.E. (1975). Markets and Hierarchies: Analysis and Antitrust Implications. New York: Free Press.

Williamson, O.E. (1981). The economics of organization: The transaction cost approach. American Journal of Sociology, 87(2), pp. 233-261.

Williamson, O.E. (1985). The Economic Institutions of Capitalism: Firms, Markets, Relational Contracting. New York: The Free Press.

Yourdon, E. (1989). Modern Structured Analysis. Englewood Cliffs, New Jersey: Prentice Hall.

Zuboff, S. (1988). In the Age of the Smart Machine. New York: Basic Books. 